\title{
Global Seismic Fragility Functions for Low-Rise RC Frames with Construction Deficiencies
}

\author{
M. Rizwan, N. Ahmad (D) J. Akbar, B. Ilyas, Arifullah, A. Ali, M. E. Ahmad, S. Pervez, \\ M. E. Rahim, and M. A. Z. Khan \\ Earthquake Engineering Center, UET Peshawar, Peshawar, Khyber Pakhtunkhwa, Pakistan \\ Correspondence should be addressed to N. Ahmad; naveed.ahmad@uetpeshawar.edu.pk
}

Received 3 September 2019; Revised 17 April 2020; Accepted 5 June 2020; Published 6 July 2020

Academic Editor: Andreas Lampropoulos

Copyright (C) 2020 M. Rizwan et al. This is an open access article distributed under the Creative Commons Attribution License, which permits unrestricted use, distribution, and reproduction in any medium, provided the original work is properly cited.

\begin{abstract}
Shake table tests were performed on three two-story $1: 3$ reduced scale RC frame structures, representative of buildings with construction deficiencies in Pakistan. The models were subjected to the natural accelerogram of the 1994 Northridge earthquake and tested under multiple scaled excitations until the models attained incipient collapse state. The models' damage mechanisms were studied, and the seismic response in terms of floor acceleration and floor displacement was retrieved. A uniform damage scale was developed for global performance assessment of considered deficient RC frames, listing average estimate of limit states' drifts and base shear coefficients, with measured uncertainty, and describing frame damage condition. Numerical frame models were prepared in finite element-based program SeismoStruct and calibrated against experimental tests. The frames were analyzed through incremental dynamic analyses. Seismic fragility functions were derived using a probabilistic-based methodology, which may be used for global damageability assessment of the considered frame building typology. Available building damage-to-loss factors were employed to transform structural damages to repair cost ratio, which were correlated with seismic intensity (repair cost ratio versus seismic intensity) to derive the seismic vulnerability curve, which may be used for the direct economic loss estimation of the considered frame building typology.
\end{abstract}

\section{Introduction}

The socioeconomic uplift of urban areas in many developing countries has necessitated the use of reinforced concrete constructions, particularly for schools, hospitals, shopping malls, and apartment buildings. It is primarily due to the abundant availability of concrete constituent materials and ease of construction of reinforced concrete buildings. However, the majority of these building stocks is lying in areas of high seismic hazard, which may be subjected to moderate-to-large damaging earthquakes in future $[1,2]$. Although the design of these structures is primarily based on the recent local or international seismic building codes, the designer-specified constructions' execution in the field still remains a challenge in developing countries, which is resulting in substandard and vulnerable building stock [3]. The recently collected data [4] from the field and construction practices in developing countries have shown a lot of construction flaws including the use of substandard quality of materials (i.e., low-strength concrete and undersized/oversized reinforcing bars), providing stirrups at larger spacing in beams and columns, lack of confining ties in beam-column joint panels, not practicing 1350 standard seismic hooks for stirrups, and using inadequate lap-splice length in the plastic hinge region, among others. Reinforced concrete structures if not built properly can result in catastrophic failure and subsequent human and economic losses, upon subjecting to earthquake-induced strong ground motions [5-12].

The recent shake table test campaign carried out by authors $[13,14]$ was considered and further analyzed in the current study for the seismic analysis and development of structural fragility functions. This included unidirectional dynamic shaking tests on the $1 / 3^{\text {rd }}$ reduced scale model with double-story RC frame structures, representing recent deficient RC frame building stock of Pakistan. In the 
construction industry, different types of prevalent defects or nonseismic provisions can be found such as substandard quality of concrete, nonseismic detailing in beam-column joint panel regions, and reduced longitudinal and shear reinforcement provisions in the beam and column members. These different defects have also been considered in this research work. The construction defects considered in test models included low-strength concrete of 2000 psi $(13.79 \mathrm{MPa})$, lack of joint shear reinforcement in joint panels, reduced longitudinal reinforcement, and larger tie spacing in beams and columns (Figure 1). Following are the characteristics of test models: story height of $12 \mathrm{ft}(3.66 \mathrm{~m})$, bay length of $18 \mathrm{ft}(5.49 \mathrm{~m})$, beams of dimensions 12 inch $\times 18$ inch $(305 \mathrm{~mm} \times 457 \mathrm{~mm})$, and columns of dimensions 15 inch $\times 15$ inch $(381 \mathrm{~mm} \times 381 \mathrm{~mm})$; steel reinforcement is provided having yield strength of $60 \mathrm{ksi}$ (415 MPa). Model-1 was conforming to code-compliant SMRF, detailed as per the requirements of [15]. However, to meet the field conditions, Model-1 was not provided with confinement ties in joint panel regions and constructed with low-strength concrete of 2000 psi (13.79 MPa). Model-2 and Model-3 were similar to Model-1, but in the former models, the beam and column shear reinforcement requirements were reduced by two and three times, respectively. Furthermore, in case of Model-2 and Model-3, to observe the effects of reduced longitudinal reinforcement defect, the beam and column members were provided with 33\% and 25\% reduced flexural rebars as compared with Model- 1 .

The as-built reduced scale models were excited with unidirectional shaking using the shaking simulator as shown in Figure 2. For the input motions initially, different records were analyzed in order to shake the simulator within the instrument limitation and also to deform the test model to full collapse state. For this purpose, the 1994 Northridge earthquake record was employed with scaled shaking excitations. During each run, the damage patterns and cracking responses of different structural members were inspected and reported. For the test model frame structures, the displacement and acceleration response were recorded through install instrumentation in the form of linear displacement transducers and accelerometers. The experimental data obtained for each test model were further analyzed to obtain the damage limit state as per the FEMA [16], which can be employed for the seismic performance assessment of the frame structures.

Nonlinear 3D numerical models based on published procedures [17, 18] have been developed in SeismoStruct [19] seismic analysis software in order to calibrate and validate the numerical results with obtained experimental data. The comparison of the numerical models' peak roof displacement (drift), acceleration values, and the corresponding damage states of the structural members has been validated with experimental recorded data. Furthermore, for the incremental time history analysis of the prototype frame numerical models, incremental dynamic analysis technique has been used for the derivation of structural fragility functions. For this purpose, various accelerograms have been downloaded from the NGA database (PEER). For the development of structural fragility functions or curves, a fully probabilistic methodology [20] was considered. The published MDR or damage-to-repair cost scales [21, 22] were chosen and used to interpret considered frame loss analysis in terms of monetary losses in the form of the seismic vulnerability curve [23]. It is worth to mention that the earlier work by Ahmad et al. [17] presented fragility functions for individual building assessment (e.g., assessing the performance of individual members like beams, columns, and joint panels), whereas the present study focuses on the derivation of fragility functions for global performance assessment, which are compatible with the FEMA [16] fragility functions given for damage assessment of portfolio of buildings.

\section{Shake Test of Deficient RC Frame Structures}

2.1. Test Models, Instrumentation, and Loading Protocols. Due to the seismic simulator limitations (load carrying and shaking capacity), 1:3 small models were designed as per the similitude and scaling requirement for simple molding representation. All the lengthwise dimensions of the structural members of the prototype structure were divided by scale factor of $\mathrm{S}_{\mathrm{L}}=3.0$ to obtain the model domain dimensions and in order to be within the limits of the shake table. The reduced scale frames were provided with additional floor masses to meet the requirements of gravity and seismic mass simulation [24]. Once mounted on the shake tabletop, the model was instrumented with accelerometers and displacement transducers for recording acceleration and displacement at the model base and floors (Figure 2).

The records of the 1994 Northridge earthquake were selected for the time history analysis because they meet the requirements of the regional tectonics (active tectonics, magnitude, and fault mechanism) and seismic simulator, i.e., maximum acceleration, velocity, and displacement remain within the allowable limit of the shake table (Figure 3 ). The models were tested using the linearly scaled accelerogram to multiple excitation levels (5\% to $100 \%$ ) for model testing. During each excitation of the shaking test, the damage responses were inspected and recorded. For each model, the shaking intensities were increased until the models were near the collapse state. The time histories of displacement and acceleration were recorded and plotted for the respective runs.

\subsection{Observed Damage Behaviour}

subjected to base motion under self-check test run with PGA equal to $0.02 \mathrm{~g}$. The frame model under this run was displaced to roof drift of about $0.20 \%$. The test frame was visually inspected for any damages after which the test model was excited with multiple scaled excitations. At 5\% run excitation, the test model was pushed to a roof drift of about $1.75 \%$, and the PGA recorded was about $0.31 \mathrm{~g}$. During this run, it was observed that, at the ground story, columns have small flexural cracks at bases, but major cracks were observed at first-story column bases. The joint panels at the ground story were observed with clear, visible, diagonal 

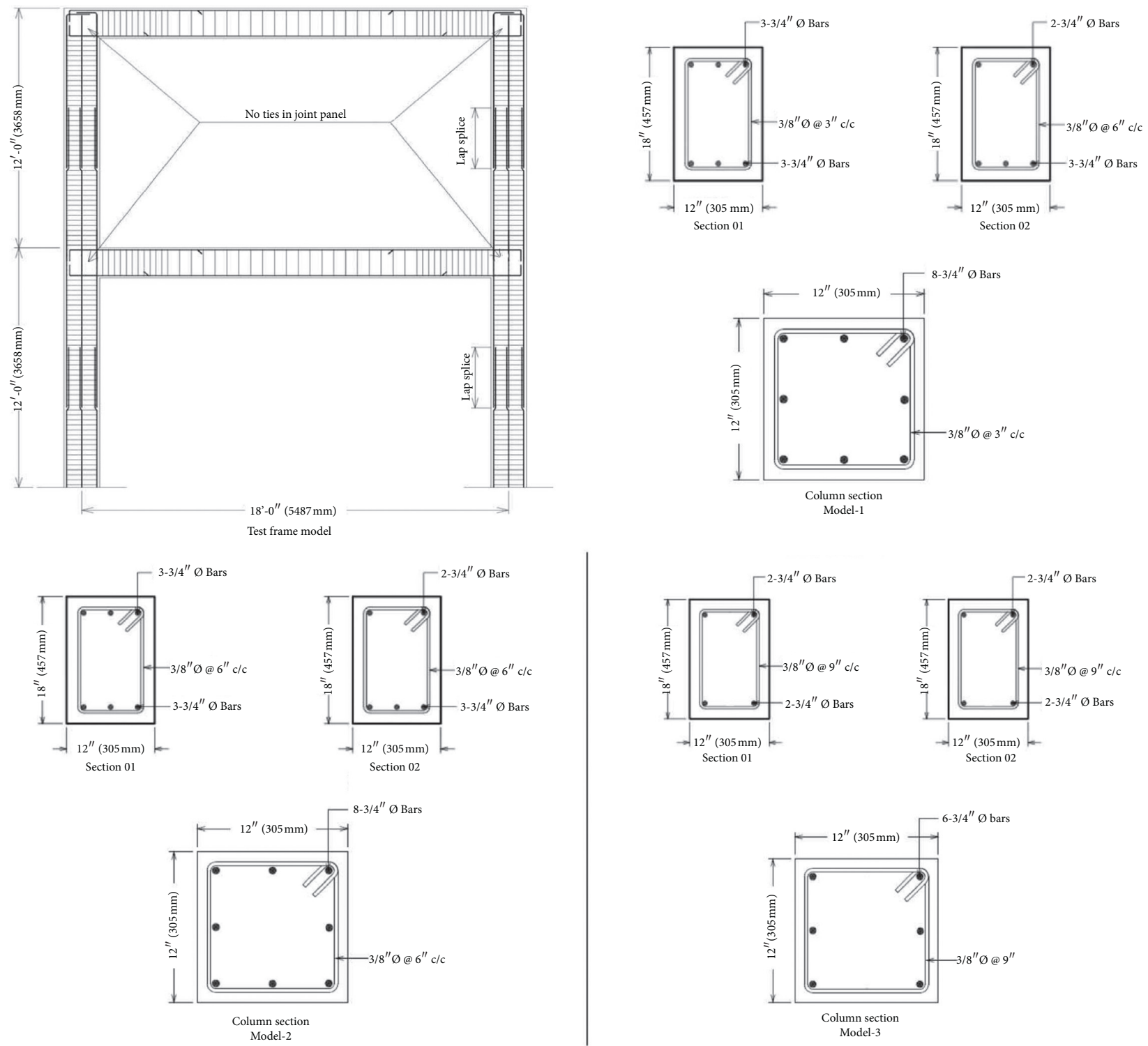

Figure 1: Layout and design configuration of considered frame structures.

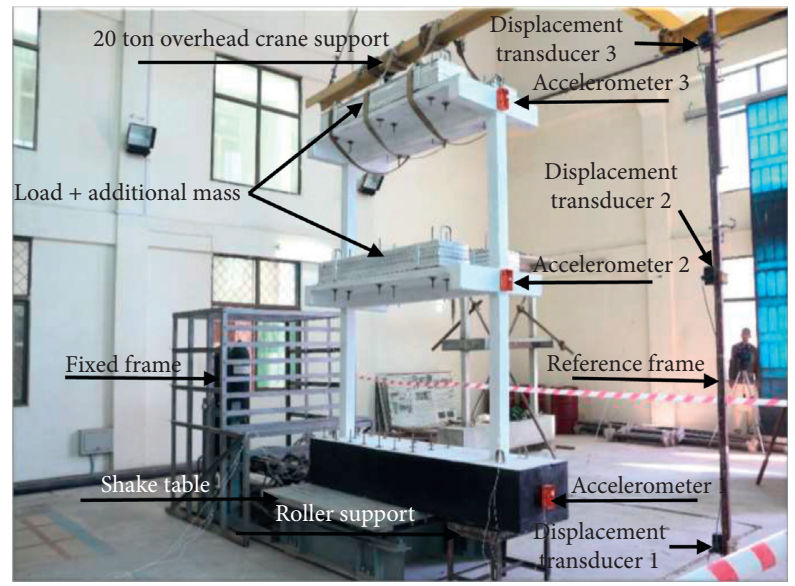

FIGURE 2: Instrumentation of the test model for acceleration and displacement recording. direction cracks. On the joint panels at the first story, small cracks were also observed with a bat-like pattern. When the test model was excited to $30 \%$ input increase excitation, the test model was found to be at the roof drift of about $2.57 \%$. The PGA value observed during this run was about $0.35 \mathrm{~g}$. Existing cracks were significantly widened during this excitation. The previous cracks in ground/top-story columns at the base and flexural cracks in first-floor beam at the ends widen further. Severe cracking was observed at ground-story joint panel regions with concrete detachment. When the test model was further shaken with a $40 \%$ increase input exaction, the test models laterally displaced to a roof drift of about $4.77 \%$ with PGA of $0.73 \mathrm{~g}$. All the existing damages were aggravated significantly. The ground-story columns were observed with concrete crushing and spalling at the base. Concrete spalling and detachment were observed at the joint panel regions of 


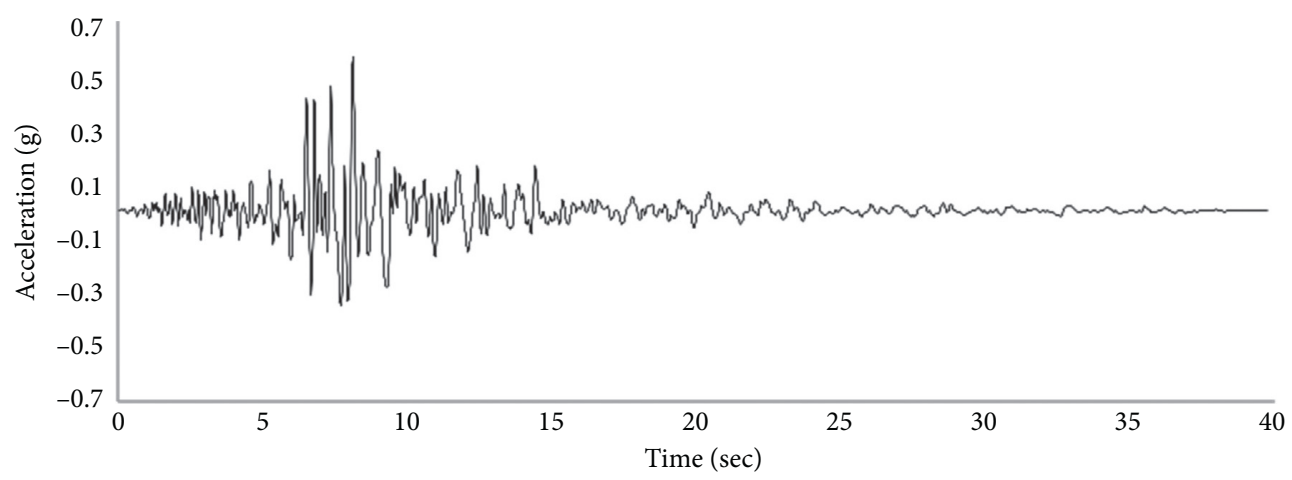

Northridge 1994 acceleration time history

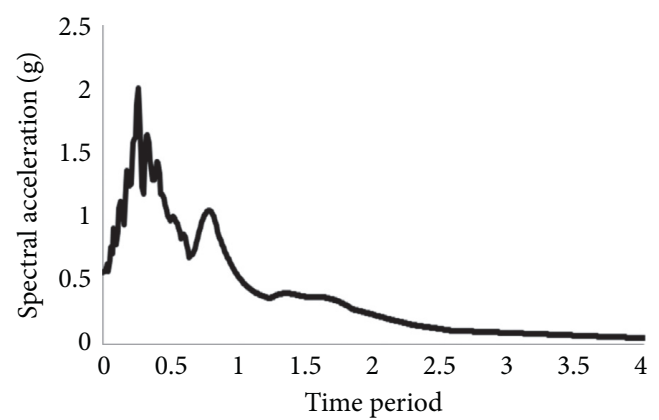

5\% damped acceleration response spectra

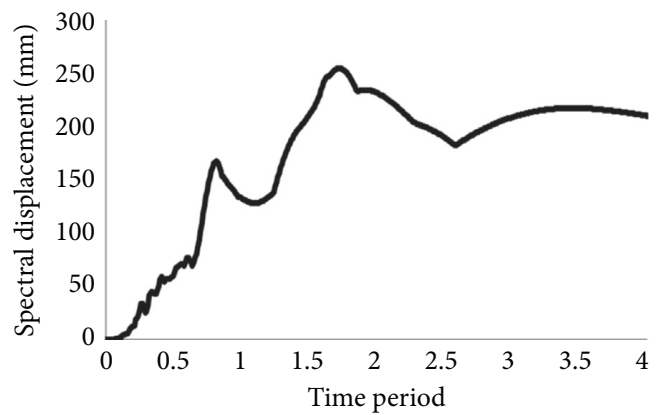

$5 \%$ damped displacement response spectra

FIgURE 3: Input excitation and response spectra (figure is reproduced from Ahmad et al. [13]).

the ground. The first-story joint panel regions were extremely damaged and with concrete spalling at the base. After this excitation, the test model was near to the collapse stage, and the testing program was stopped. Table 1 reports the observed response and damage condition of Model 1 for multiple excitation levels, and Figure 4 shows the observed damages of the model.

Model-2: initially, test Model-2 was excited with the shake table automatic shaking called self-check which has displaced the frame model to drift of $0.05 \%$. No visible cracks were observed during this run. After the self-check run, the test model was excited with multiple scaled excitations. During the 5\% run excitation, the test model was laterally deformed to a drift value of $1.13 \%$. After the run, the test model was inspected for any damages observed during the shaking. It was observed that, during the $5 \%$ run, small flexural cracking was visible at the structural components, i.e., beam and column ends. On the joint panel region of the ground level, hair-like cracks were also visible. After the 5\% run, the test model was further excited with $10 \%$ of the input acceleration records during which the test model was observed at a roof drift of about $2.12 \%$. It was observed that, during the $10 \%$ run, the flexural cracks already developed at the beam and column member end were widened. It was also observed that the joint panel region on the ground-story level experienced aggravated cracks developed during the previous run. It was also observed that, during this run, the first-story level joint panel regions experienced with hairline diagonal direction cracks with concrete cover detachment. Some amount of concrete crushing at column ends of the ground level were also observed during the $10 \%$ run excitation. After that, the test model was further excited with 30\% shaking during which the test model was deformed to a drift of about $3.45 \%$. During 30\% run, the existing cracks in beam-column joints further aggravated at both floor-levels. It was also observed that the cracking of the first-level joint panel regions was severely damaged as compared with the ground joint levels. The joints of the model during this run were severely damaged; however, damage to top-story joints was comparatively more than the ground story. It is due to the fact that the total beam-end moment of the firststory beam is transferred to a single column through the joint panel, subjecting the joint panel to large shear arising principle tensile stresses in concrete. Unlike, beam-end moments at the ground story are transferred to columns above and below the connection. Furthermore, ground-story exterior connection joint panels $(+)$ have confinement factor higher than the exterior roof connection joint panel $(T)$. The existing cracking response on the beam and column ends was significantly aggravated during this run, and the test model was found to be near the collapse state after this shaking.

The damage response of test Model 2 was quite equal to the Model 2 response, but the damage patterns in case of Model 2 were observed during low-drift demands as 
TABLE 1: Observed response and damage condition of Model-1 under significant runs.

\begin{tabular}{lcccc}
\hline $\begin{array}{l}\text { Run } \\
(\%)\end{array}$ & $\begin{array}{c}\text { Roof } / 1^{\text {st }} \text { story } \\
\text { displacement, inch }(\mathrm{mm})\end{array}$ & $\begin{array}{c}\text { Roof/ } 1^{\text {st }} \text { story } \\
\text { drift }(\%)\end{array}$ & $\begin{array}{c}\text { Base shear } \\
\text { kips }(\mathrm{kN})\end{array}$ & Damage pattern \\
\hline 5 & & $\begin{array}{l}\text { (i) Ground-story column base observed with small flexural cracks. } \\
\text { (ii) Major cracks were observed at the first-story column base. }\end{array}$ \\
& 1.75 & $26.51(117.92)$ & $\begin{array}{l}\text { (iii) On the ground story, clear visible diagonal direction cracks. } \\
\text { (iv) On the joint panels at the first story, small cracks were also } \\
\text { observed with a bat-like pattern. }\end{array}$ \\
\hline
\end{tabular}

(i) Existing cracks were significantly widened during this excitation.

(ii) The column base cracks were further widened at both stories as well as the flexural vertical.

(iii) Horizontal cracking at beam member ends.

(iv) Severe cracking was observed at ground-story joint panel regions with concrete detachment.

(i) All the existing damages were aggravated significantly.

(ii) The columns' base was observed with severe concrete crushing and spalling with more severity at ground-story column bases.

(iii) Concrete spalling and detachment were observed at the joint panel regions of the ground.

(iv) The first-story joint panel regions were extremely damaged and with concrete spalling at the base.(v) After this excitation, the test model was near to the collapse stage.

compared with the drift demands on Model 1. Table 2 shows the damage conditions for major excitation runs, whereas Figure 5 shows structural members and joint panel damages.

Model-3: similar to Model-1 and Model-2, this frame model was also initially excited with the simulator selfcheck excitation to drift of about $0.014 \%$, and no visible cracks were found during this run. After the self-check run, the test model was excited with $5 \%$ of the input excitation during which the frame model was deformed to a drift value of $0.36 \%$. Upon visual inspection, it was observed that, during this run, the column ends on the ground and first levels experienced flexural hair cracking. The ground-story level longitudinal beams were also observed with vertical cracks at member ends. When the test model was subjected to input excitation level of $30 \%$, the test frame was found to be in the roof drift value of about $1.31 \%$. Already appeared cracks on the structural members were further enhanced and widened in flexure. When the frame model reaches to the input excitation of $60 \%$, the test model was found to be lateral at a roof drift value of $3.92 \%$. During this input shaking, the test frame experiences significant damages in the structural members (beam and columns) as well as the joint panel regions. It was observed that, during this exaction, the column bases experienced significant cracking and cover concrete spalling. Similarly, the beam member end at both the ground story level and also at the first story level sustained vertical and horizontal cracking. It was observed that ground-story level joint panel regions experienced major cracking and with concrete cover spalling and detachments at bottom levels. After this run, the test model was near the collapse stage, and the testing program was stopped. The damage pattern of odel-3 observed during the experimental testing shows a quite similar nature of damages of the structural components, i.e., beam and column members as well as the damage response of the joint panel regions. However, it was observed that, as in the case of Model-2, the damage pattern appears to be on much lower shaking demands as compared with the other two models. The experimental observed damage response in test Model3 has been reported in Table 3 and Figure 6.

\section{Development of Damage Scale}

3.1. Prototype Frame Force-Deformation Relationships. For all the models and for each run, the experimental data were recorded and were further processed to obtain the model domain acceleration and displacement values. For this, the measured response was corrected with the corresponding instrument sensitivity in order to compute the recorded data in the units of length (i.e., inch $/ \mathrm{mm}$ ) and acceleration (i.e., g). Furthermore, each model test data (for each run), the recorded displacement and acceleration histories were processed for noise filtering through the analytical filter and baseline corrections. The filter processing and the baseline adjustments were performed in data analysis software SeismoSignal [19]. Similarly, in order to compute the displacement values at the ground and first story levels, the respective displacement histories were normalized with respect to the displacement histories obtained at the base pad level. The measured absolute displacement response of each floor was transformed to relative displacement response with reference to the base of frame. This was processed to compute the inter-story drift, dividing the relative displacement of each story by the story height. The peak values were identified for each story. The interstory shear or inertial forces at each ground and first story level were obtained by multiplying floor masses (self- 
TABLE 2: Observed response and damage condition of Model-2 under significant runs.

\begin{tabular}{|c|c|c|c|c|}
\hline $\begin{array}{l}\text { Run } \\
(\%)\end{array}$ & $\begin{array}{c}\text { Roof } / 1^{\text {st }} \text { story } \\
\text { displacement, inch }(\mathrm{mm})\end{array}$ & $\begin{array}{c}\text { Roof/ } 1^{\text {st }} \text { story } \\
\text { drift }(\%)\end{array}$ & $\begin{array}{l}\text { Base shear } \\
\text { kips }(\mathrm{kN})\end{array}$ & Damage pattern \\
\hline 5 & 3.15 (79.97) & 1.13 & $22.87(101.72)$ & $\begin{array}{l}\text { (i) It was observed that small flexural cracking was visible at the } \\
\text { structural components, i.e., beam and column ends. } \\
\text { (ii) On the joint panel region of the ground level, hair-like cracks were } \\
\text { also visible. }\end{array}$ \\
\hline 10 & $5.91(150.23)$ & 2.12 & $30.59(135.82)$ & $\begin{array}{l}\text { (i) The flexural cracks already developed at the beam and column } \\
\text { member end were widened. } \\
\text { (ii) It was also observed that the joint panel region on the ground story } \\
\text { level experienced aggravated cracks. } \\
\text { (iii) It was also observed that, during this run, the first-story level joint } \\
\text { panel regions experienced moderate cracking in diagonal direction } \\
\text { cracks with concrete cover detachment. } \\
\text { (iv) Some amount of concrete crushing at column ends of the ground } \\
\text { level was also observed. }\end{array}$ \\
\hline 30 & $9.63(244.57)$ & 3.45 & $34.25(152.33)$ & $\begin{array}{l}\text { (i) The joint panel regions on the ground level and as well as on the first } \\
\text { story level significantly enhanced and spread. } \\
\text { (ii) It was also observed that cracking of the first-level joint panel } \\
\text { regions was severely damaged as compared with the ground joint } \\
\text { levels. } \\
\text { (iii) The joints of the model during this run were severely damaged; } \\
\text { however, damage to top-story joints was comparatively more than the } \\
\text { ground story. }\end{array}$ \\
\hline
\end{tabular}

TABLE 3: Observed response and damage condition of Model-3 under significant runs.

\begin{tabular}{|c|c|c|c|c|}
\hline $\begin{array}{l}\text { Run } \\
(\%)\end{array}$ & $\begin{array}{c}\text { Roof/ } 1^{\text {st }} \text { story } \\
\text { displacement, inch }(\mathrm{mm})\end{array}$ & $\begin{array}{c}\text { Roof } / 1^{\text {st }} \text { story } \\
\text { drift }(\%)\end{array}$ & $\begin{array}{l}\text { Base shear } \\
\text { kips }(\mathrm{kN})\end{array}$ & Damage pattern \\
\hline 5 & $1.01(25.65)$ & 0.36 & $8.08(35.96)$ & $\begin{array}{l}\text { (i) It was observed that, during this run, the column ends on the } \\
\text { ground and first level experienced flexural hair cracking. } \\
\text { (ii) The ground-story level longitudinal beams were also observed with } \\
\text { vertical cracks at member ends. }\end{array}$ \\
\hline 30 & $3.66(92.95)$ & 1.31 & $18.73(83.31)$ & $\begin{array}{l}\text { (i) Already appeared cracks on the structural members were further } \\
\text { enhanced and widened in flexure. } \\
\text { (ii) Beam-end horizontal direction crack spreading. }\end{array}$ \\
\hline 60 & $10.93(277.60)$ & 3.92 & $28.07(124.84)$ & $\begin{array}{l}\text { (i) It was observed that, during this exaction, the column bases } \\
\text { experienced significant cracking and cover concrete spalling. } \\
\text { (ii) The beam member end at both the ground story level and also at } \\
\text { the first story level sustained vertical and horizontal cracking. } \\
\text { (iii) It was observed that ground-story level joint panel regions have } \\
\text { experienced major cracking and with concrete cover spalling and } \\
\text { detachments at bottom levels. }\end{array}$ \\
\hline
\end{tabular}

weight + additional mass weight) with the corresponding maximum values of the accelerations during each test run. The ground and first story interstory shear forces were added to compute the total base shear force at the base of the structure. All the previous data have been analyzed in the model domain. In order to obtain the prototype domain displacement and acceleration values (base shear values), the correction factors of the similitude and scaling requirements were used and were multiplied with model domain data. The maximum values of displacement and base shear force for each run were correlated in order to develop the structural frame force-deformation relationships called capacity curves or envelope curves. Figure 7 shows the capacity curves obtained for the corresponding prototype frame structures. It is worth mentioning that, unlike the present study, the previous studies by Rashid and Ahmad and Rizwan et al. $[3,14]$ considered the peak displacement and peak base shear force observed in each run for derivation of max. force-displacement envelop and calculation of $R$ factor. Due to the present idealization procedure, the capacity curves derived in the present study do not show hardening behavior, particularly for Model-1 and Model-2, as observed in previous studies $[3,14]$, but rather more plastic/softening behavior.

3.2. Elastic-Plastic Idealization of Capacity Curves. In order to develop the representative building typology prototype frame average force-deformation relationships and a general damage state scale, the capacity curves obtained in Figure 7 were normalized using the bilinear equivalent energy balance procedures as shown in Figure 8. For each considered frame structure, the peak displacement obtained from the experimental record was used as the maximum deformation 


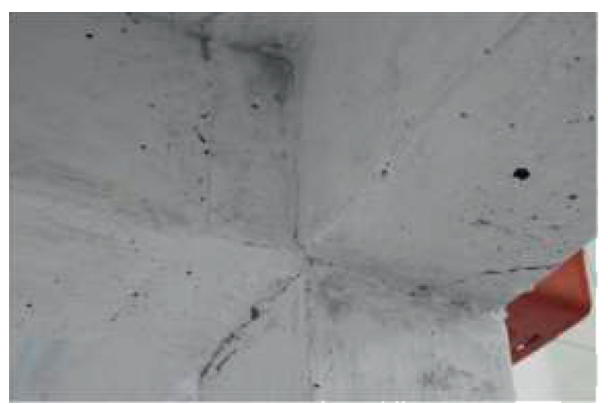

Flexure cracks in beams and columns, ground storey

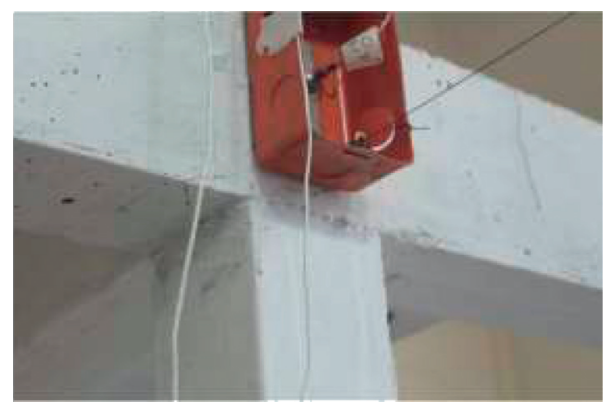

Slight cracks in joint panel on ground storey

Damages observed in columns, beam and joint panels during $5 \%$ run

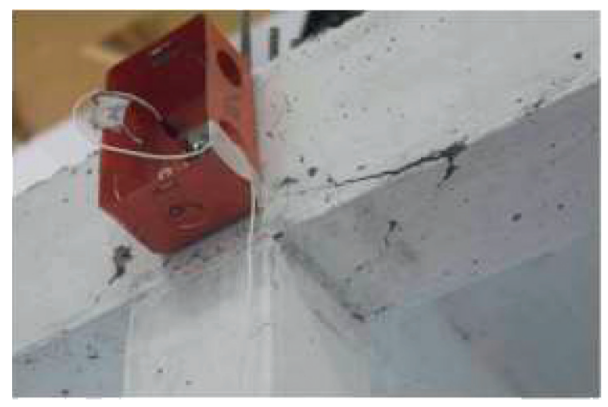

Severe bat-like cracks in joints on first storey

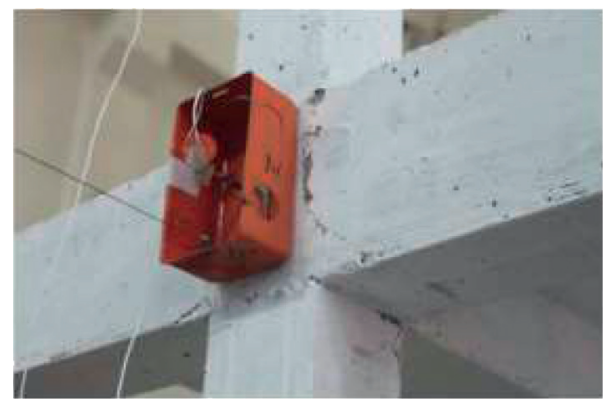

Damage progress in joint panel on ground storey

Damages observed in joint panels of ground and first storey during $30 \%$ run

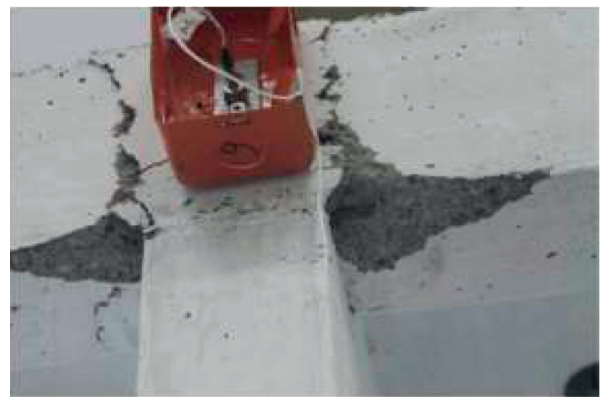

Cover detachment and damage in joint on first storey

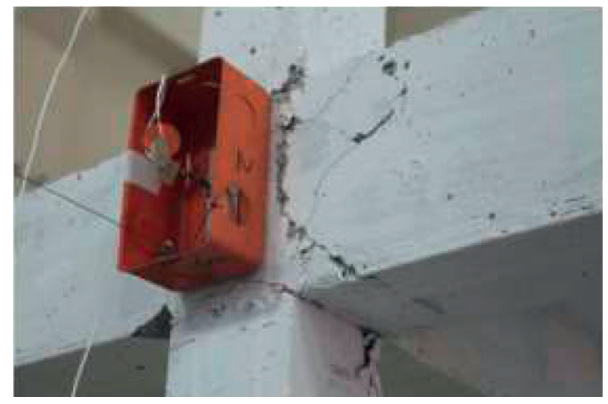

Severe damage to joint panel on ground storey

Damages observed in joint panels of ground and first storey during $40 \%$ run

Figure 4: Observed damages in Model-1 (refer Table 1 for damage evolution; figure is reproduced from Ahmad et al. [13]).

capacity of the frames. The energy balance procedures use an iterative technique in order to equalize the energy (i.e., area occupied by the curve) under the actual force-deformation curves and the corresponding bilinear idealized curves (Figure 8). Figure 9 shows the developed bilinear forcedeformation relationships for the prototype frames. For each test frame structure, the value of yield deformation, yield strength, ultimate strength, and ultimate deformations were obtained from Figure 9. It is worth to mention that the earlier investigations on code noncompliant reinforced frame structure [3] test data were also included in the development of force-deformation relationships as shown in Figure 9.
3.3. Damage Limit States: Drift Limits, Base Shear Coefficients, and Damage States. In order to perform the structural or global seismic evaluation, it is required to derive actual or experimental-based damage scale which is mostly specified in terms of force-displacement limits and the corresponding damage states of the components of a structural system. The damage scale is also used to specify specific performance levels. For the development of drift-based damage scale sates, the current work adopted the damage performance levels as per the FEMA [16]. The FEMA [16] specify various limit states, i.e., slight, moderate, significant, and near collapse states, for damageability assessment of buildings. In the current studies, the damage scale states were coupled with 


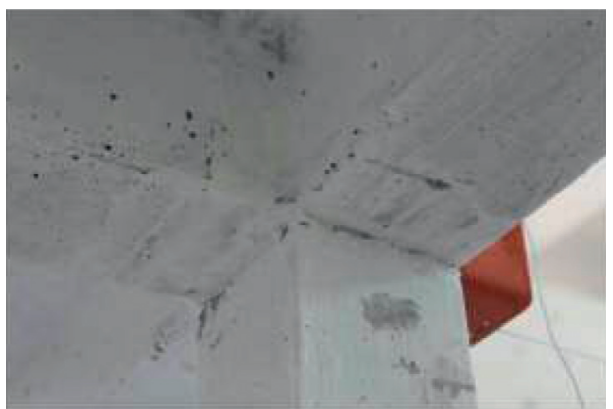

Flexure cracks in beam and column, ground storey

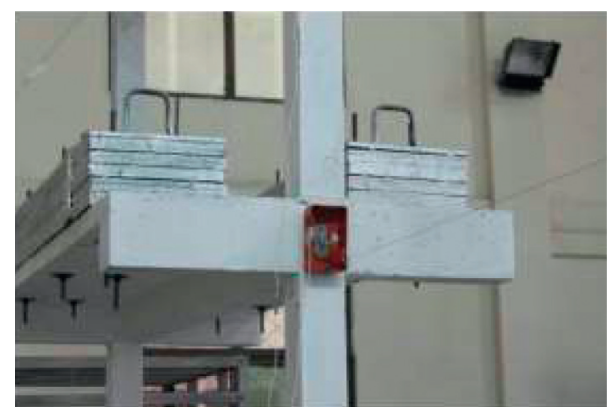

Cracks in joint panel on ground storey

Damages observed in columns, beam and joint panels during 5\% run

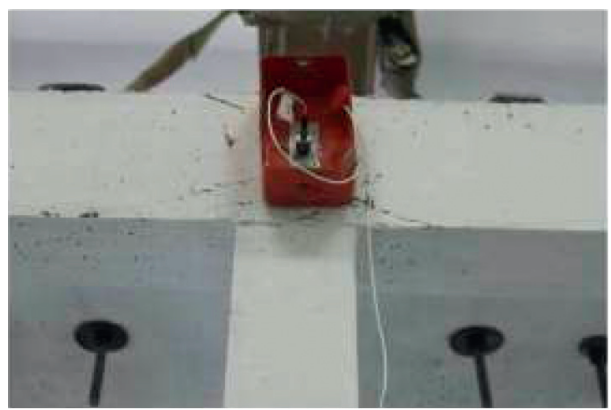

Severe bat-like cracks in joints on first storey

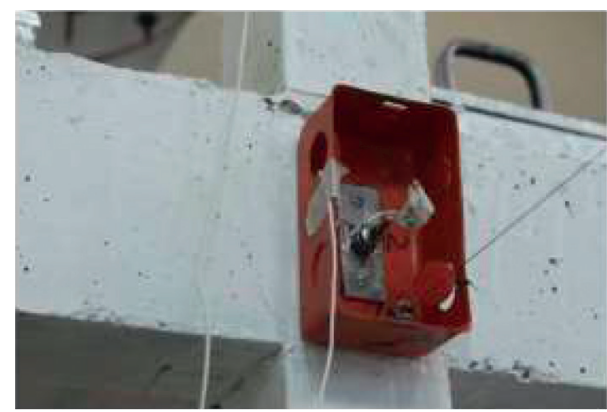

Damage progress in joint panel on ground storey

Damages observed in joint panels of ground and first storey during $10 \%$ run

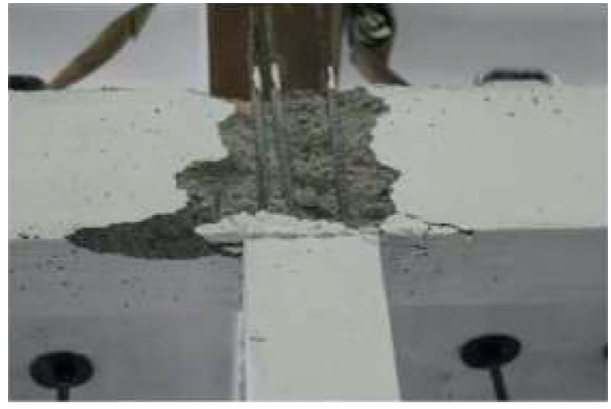

Cover detachment and spalling in joint on first storey

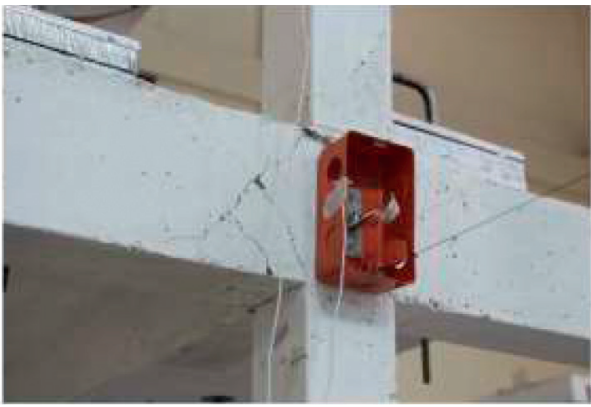

Significant damage to joint panel on ground storey

Damages observed in joint panels of ground and first storey during 30\% run

Figure 5: Observed damages in Model-2 (refer Table 2 for damage evolution; figure is reproduced from Ahmad et al. [13]).

the peak roof deformation or drift. However, the force limit states in terms of strength have been specified in the form of base shear coefficient, which is the ratio of total base shear and total weight of the structure. The drift limits for the test frame were considered, the corresponding performance levels as per the FEMA [16] were analyzed, and the seismic parameter in the form of yield and ultimate strength and deformations have been obtained from the developed capacity curves. Similarly, the drift limit states corresponding to the base shear coefficient values have been obtained directly from the force-deformation capacity curves. Some adjustments in the form of sorting drift values were also performed in order to obtain the average performance levels, and accordingly, a polynomial function trend line was used for different points on the capacity curves as shown in Figure 10. The curve data were truncated with respect to a roof drift value of $3.70 \%$ for averaging purposes. The damage scale developed for the considered frames are reported in Table 4.

\section{Numerical Modeling of RC Frame Structures}

4.1. Reinforced Concrete Frame Inelastic Modelling in SeismoStruct. In order to evaluate the seismic response of the reinforced concrete structural system, it is essential to develop nonlinear numerical models which can then be analyzed by static or dynamic analysis which is essential for the seismic performance evaluation. For inelastic modeling and dynamic time history analysis of the representative prototype frame structures, numerical models have been developed in SeismoStruct seismic analysis software [18, 25]. The developed model was matched against the shake table test experimental data. The modeling technique has been discussed in the earlier work of Ahmad et al. [17]; only the 


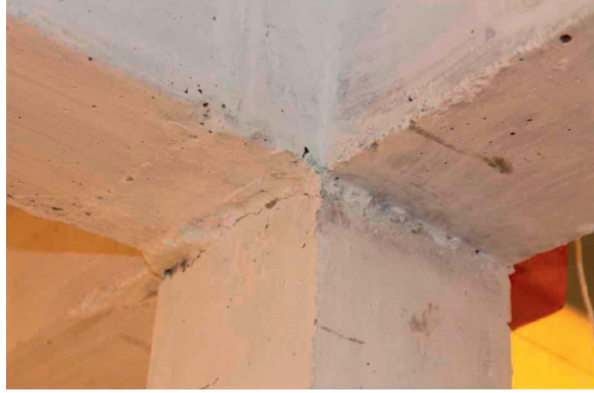

Flexure cracks in beam and column, ground storey

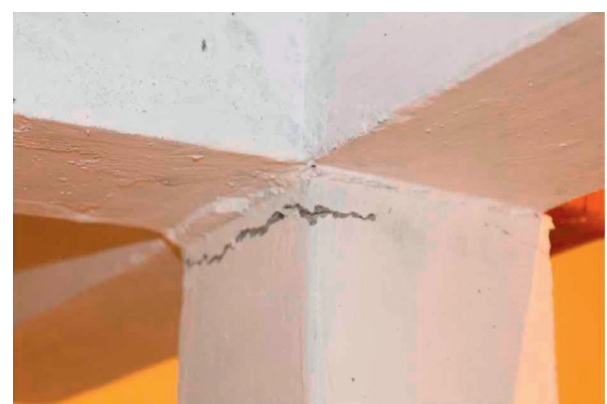

Cracks in top ends of columns first storey

Damages observed in beams and columns during 5\% run

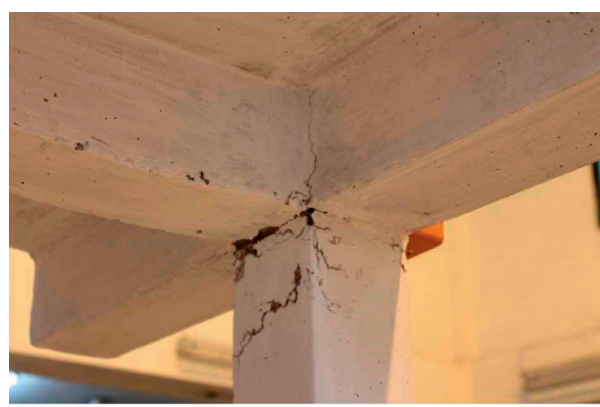

Concrete crushing at column top ends, ground storey

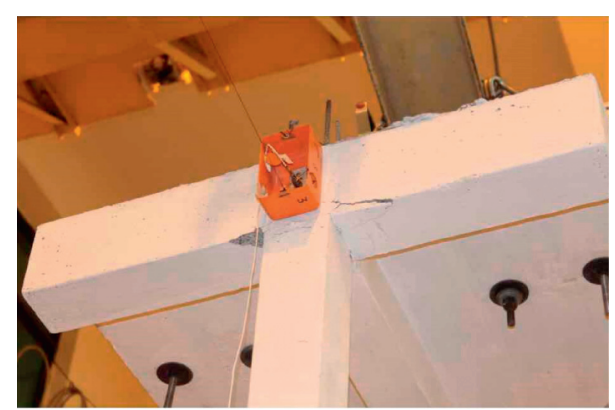

Cover concrete detachment from joints on first storey

Damages observed in column ends on ground storey and joint panels of first storey during 50\% run

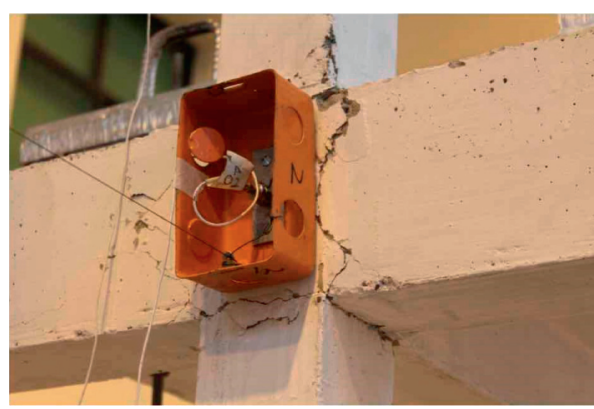

Extend of damage to joints on ground storey

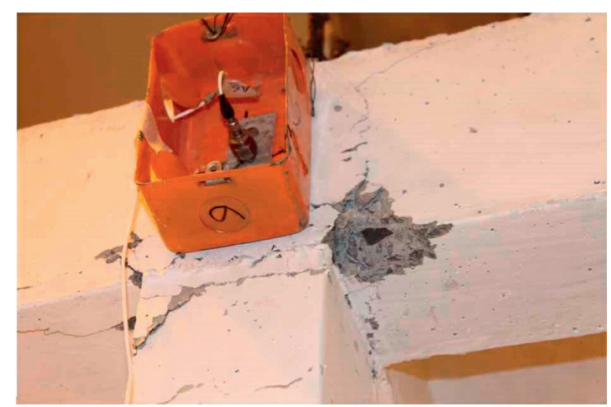

Extend of damage to joints on first storey

Damages observed in joint panels of ground and first storey during $60 \%$ run

Figure 6: Observed damages in Model-3 (refer Table 3 for damage evolution; figure is reproduced from Ahmad et al. [13]).

nonlinear shear strength simulation and formulation have been further discussed for generalization as shown in Figure 11.

Different approaches based on numerical studies and experimental investigations (Kim and LaFave, 2012; Kurose, 1987; [30, 31]) have been reported in the literature to simulate the joint panel shear strength $\left(\tau_{j h}\right)$ response. In the current nonlinear modeling and simulation of shear behavior of the beam-column joint panels, the shear strength-deformation analytical models developed from the study of Kim and LaFave [28] have been adopted. These analytical equations have been developed and validated based on a number of experimental studies and addressed also the nonseismically detailed joints as common in the existing deficient buildings. The modeling of the shear strength and deformation limit capacities have been shown in Figure 12 with the [32] cyclic constitutive relationships. The model proposed by Kim and LaFave (2012) correlated the joint panel shear strength and shear deformation for different key points on the moment-rotation or force-deformation constitutive plot. For the peak point, the shear strength $\tau_{j h}$ and the corresponding shear deformation $\gamma_{\mathrm{j}}$ are given by equations (1) and (2), respectively. These analytical equations mainly depend on the joint panel dimensions, concrete strength in compression, the amount reinforcement in the beam, and confining ties in joint panel regions. 


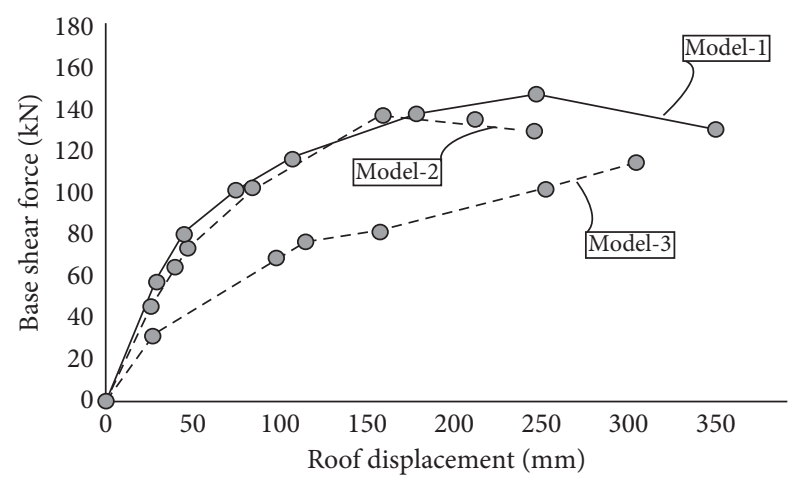

FIGURE 7: Developed prototype frame force-deformation relationships.

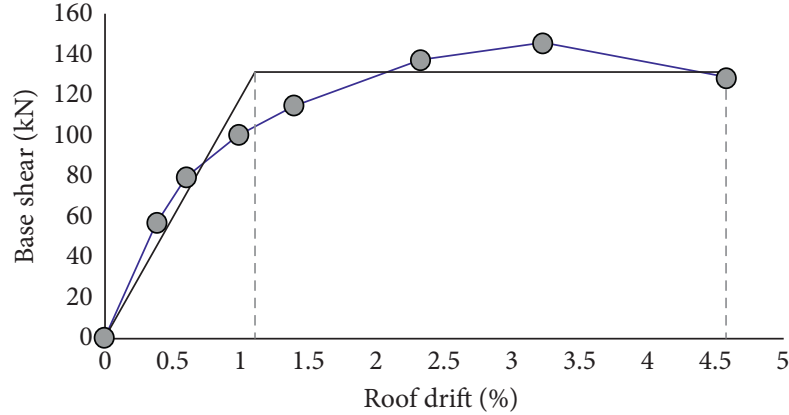

(Model-1)

(a)

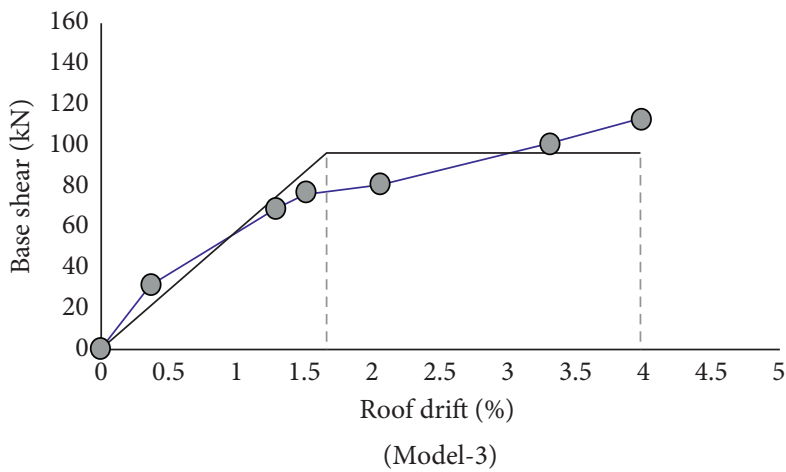

(c)

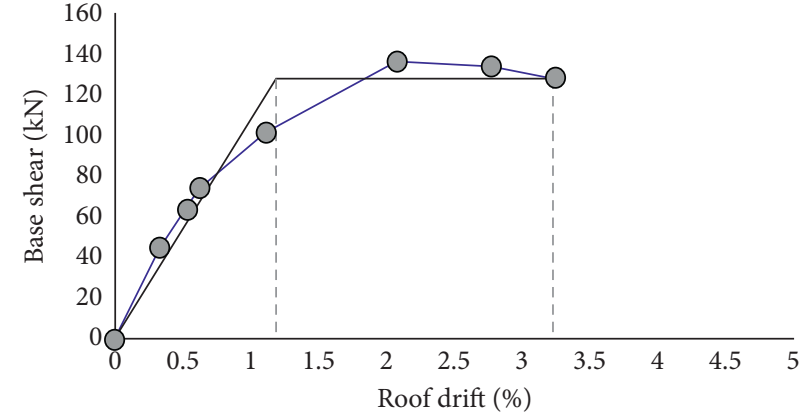

(Model-2)

(b)

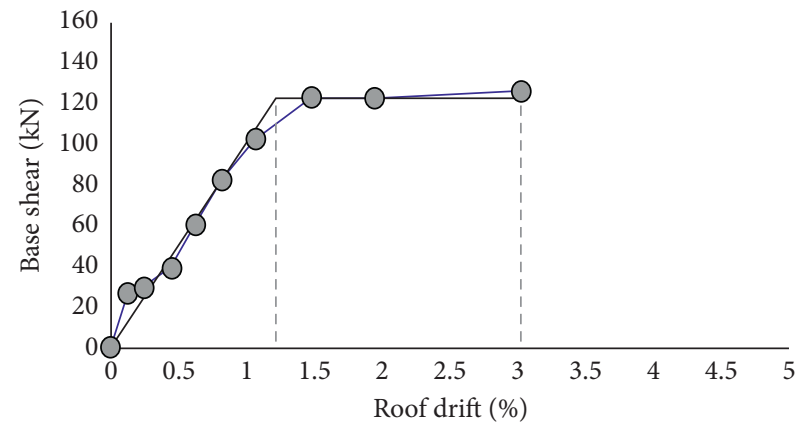

(Model, Ahmad et al. 2017)

(d)

FIGURE 8: Test data set force-deformation relationship bilinear idealizations.

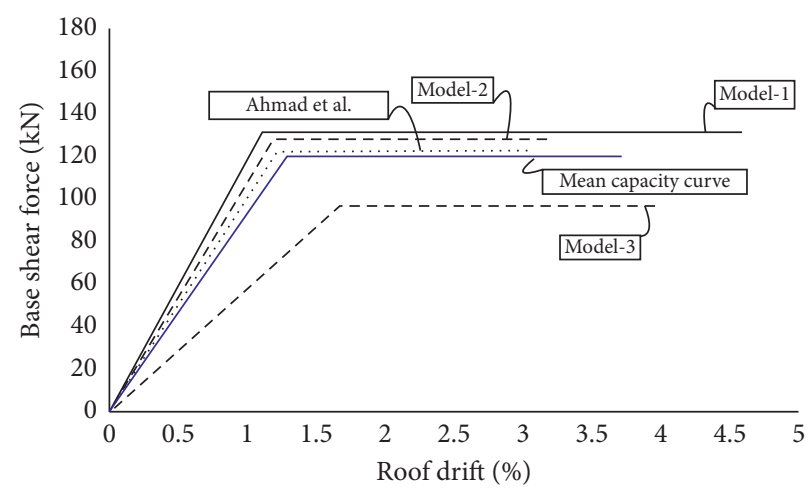

Figure 9: Developed elastic-plastic force-deformation relationships. The frame tested by Ahmad et al. [25] was also considered in the present study. 


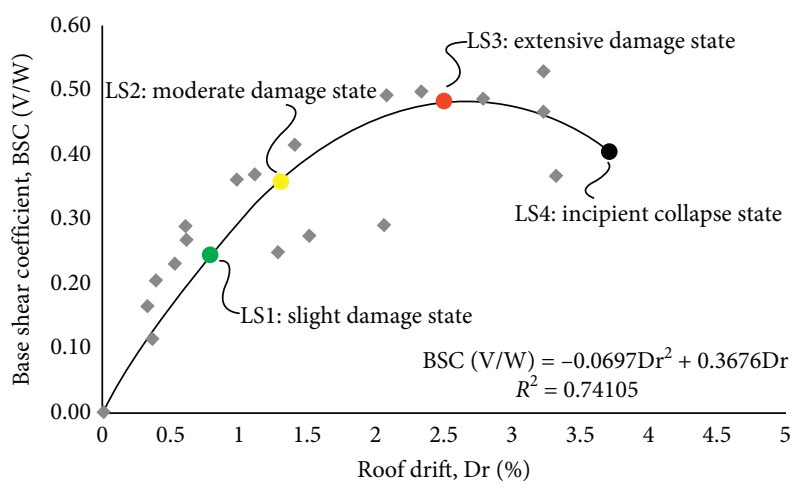

FIGURE 10: Development of base shear coefficient (BSC) and roof drift for averaging and respective damage limits.

TABLE 4: Considered frame typology damage-specified performance level [26].

Limit states for observed damage
Roof drift (\%)

Base shear coefficient

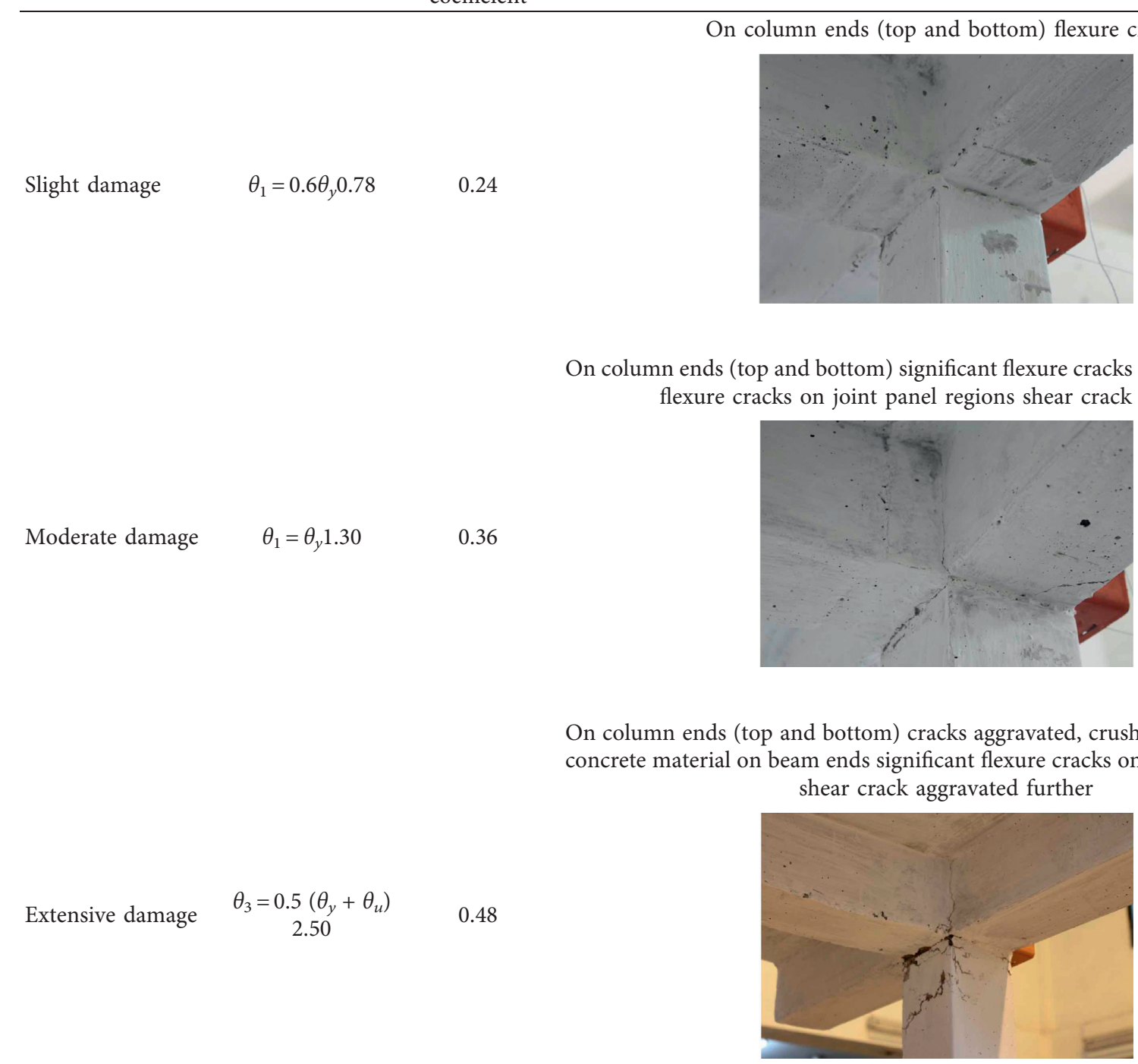


TABLE 4: Continued.

\begin{tabular}{llll}
\hline $\begin{array}{l}\text { Limit states for } \\
\text { observed damage }\end{array} \quad$ Roof drift (\%) & $\begin{array}{l}\text { Base shear } \\
\text { coefficient }\end{array}$ & $\begin{array}{l}\text { On column ends (top and bottom) cracks aggravated, crushing with spalling of } \\
\text { concrete material on beam ends significant flexure cracks major shear cracking } \\
\text { on the joint panel regions with significant concrete detachment. }\end{array}$ \\
\hline Incipient collapse & $\theta_{1}=\theta_{u} 3.70$ & 0.41 & Description of damage
\end{tabular}

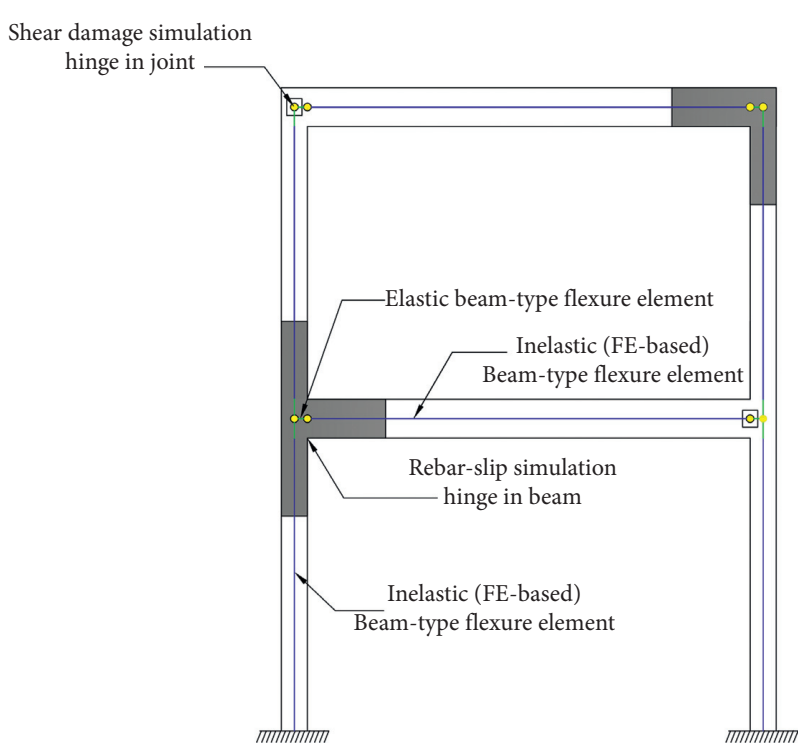

Figure 11: Development of the nonlinear numerical model for frame structures [17].

$$
\begin{aligned}
& \tau_{j}(\mathrm{MPa})=\alpha_{t} \beta_{t} \eta_{t} \lambda_{t}(\mathrm{JI})^{0.15}(\mathrm{BI})^{0.30}\left(f^{\prime} c\right)^{0.75}, \\
& \gamma_{j}(\mathrm{rad} .)=\alpha_{\gamma t} \beta_{\gamma t} \eta_{\gamma t} \lambda_{\gamma t} \mathrm{BI}(\mathrm{JI})^{0.30}\left(\frac{\tau_{j}}{f^{\prime} c}\right)^{-1.75} .
\end{aligned}
$$

The joint panel shear strength-deformation constitutive models given in equations (1) and (2) are for the peak point, whereas the cracking, yield, and postultimate stages of the moment-rotation curves can be obtained by multiplying the factors with peak strength and deformation values, as mentioned in Table 5. The corresponding shear-stress state was then employed to find the moment-rotation capacity $(\mathrm{M} y)$ of the shear hinge modeled in the nonlinear numerical simulation of the considered frame structures shown in Figure 12.
4.2. Numerical Models' Calibration. 3D numerical models of the prototype frames were simulated in SeismoStruct seismic analysis software by modeling different structural components, i.e., in-plane beams, transverse beams, columns, and slab members. For the structural members, the material in elasticity and the P-delta effects were considered by software. The joint panel region was modeled through a shear hinge spring whose moment capacity was computed as mentioned earlier. The numerical models were imposed with gravity loads and $25 \%$ live loads. The base acceleration time histories recorded during the experimental stages were then used for the time history analysis to compare and validate the developed numerical model with the experimental results. From time history analysis of each model, the peak values of displacement, acceleration, and damage patterns in terms of the bar-slip response and joint panel sheer response have been obtained and compared with experimental results. Figure 13 shows the numerical model developed in SeismoStruct software, whereas Figure 14 shows the numerical and experimental comparison of roof displacement time histories.

\section{Seismic Fragility Functions}

5.1. Incremental Dynamic Analysis. For the development of frame numerical-based structural capacity curves and seismic response curves, the incremental dynamic analysis (IDA) technique with various accelerograms have been employed in the current study [33]. The IDA-based structural response curves and capacity curves have been further analyzed in order to develop the probability of specified limit state exceedance. The limit probability exceedance for the prototype frame structures has been developed based on the fragility development technique (NDRM) [20]. The numerical frame model (IDA) was performed in SeismoStruct seismic analysis software using different accelerograms downloaded from the NGA database (PEER). The developed IDA-based structural capacity curves and seismic response 


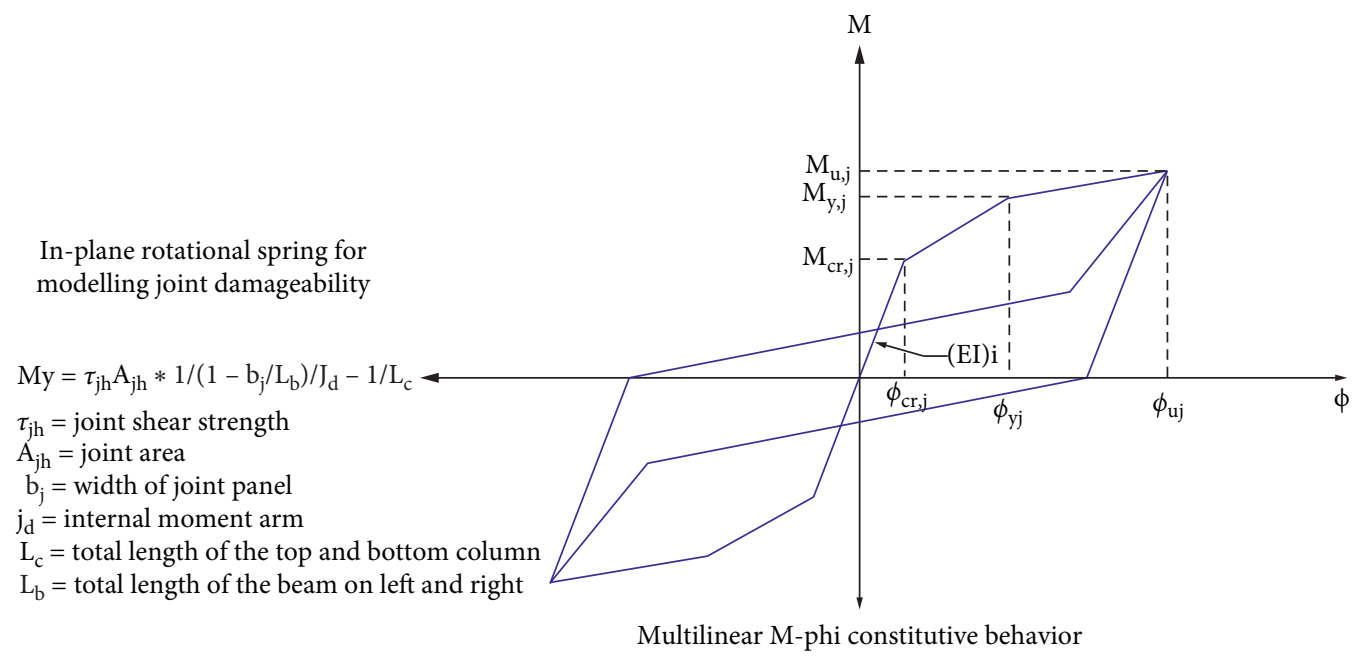

FIGURE 12: Joint panel shear hinge constitutive model [17].

TABLE 5: Joint panel shear strength-deformation analytical equations developed by Kim and LaFave (2012).

\begin{tabular}{|c|c|c|c|c|c|c|}
\hline \multirow{2}{*}{ Parameters } & \multicolumn{2}{|c|}{ Cracking } & \multicolumn{2}{|c|}{ Yielding } & \multicolumn{2}{|c|}{ Maximum } \\
\hline & $\tau_{\mathrm{cr}}$ & Std. & $\tau_{y}$ & Std. & $\tau_{\max }$ & Std. \\
\hline$\tau(\mathrm{MPa})$ & $0.442 \times \tau_{j(\max )}$ & 0.299 & $0.890 \times \tau_{\mathrm{j}(\max )}$ & 0.154 & $\tau_{\mathrm{j}(\max )}$ & 0.153 \\
\hline$\gamma$ (rad.) & $0.0197 \times \gamma_{j(\max )}$ & 0.437 & $0.362 \times \gamma_{j(\max )}$ & 0.420 & $\gamma_{\mathrm{j}(\max )}$ & 0.410 \\
\hline
\end{tabular}

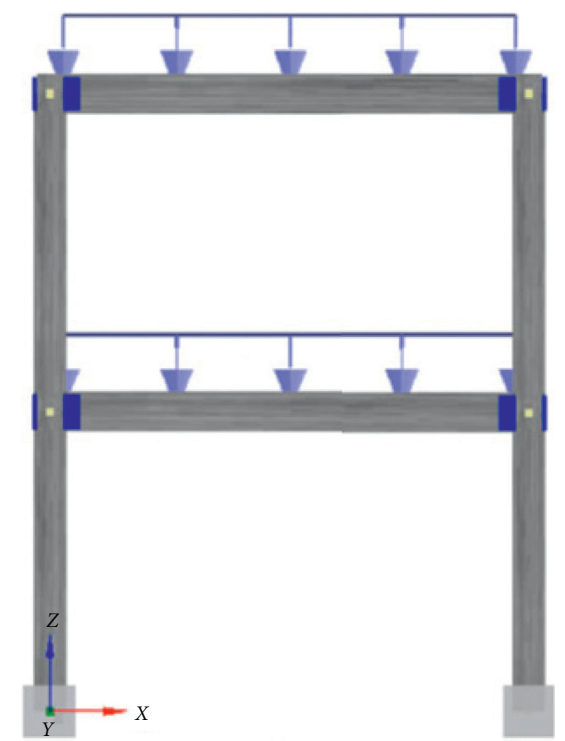

Elevation

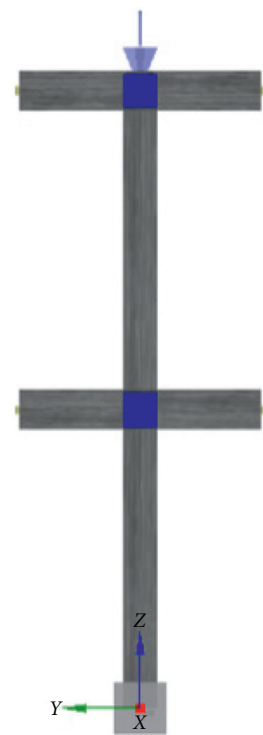

Side view

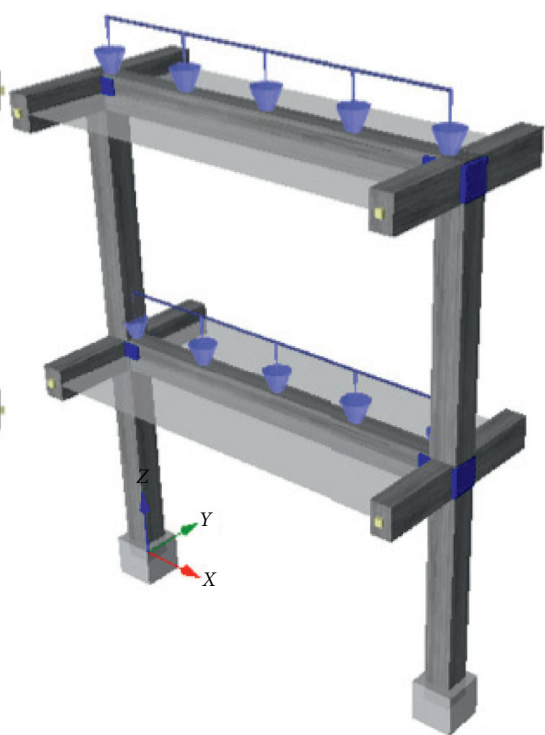

3D perspective view

FIgURE 13: Representative nonlinear model developed in SeismoStruct.

curves for the ten selected accelerograms have been shown in Figure 15.

5.2. Derivation of Fragility Functions. In order to obtain the fragility functions for the considered frame prototype structures, the first-order reliability method (FORM) has been employed [34]. The FORM technique was considered to obtain the probability of exceedance of the specified state of limiting values. For this purpose, demand-capacity values in terms of specified limit states were computed as given in the following equation: 


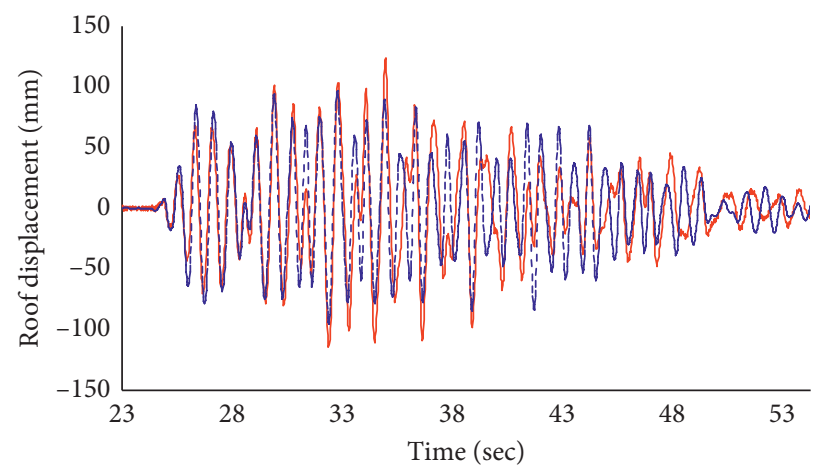

Model-1, 1.75\% roof drift (exp.)

— Experimental

- - Analysis

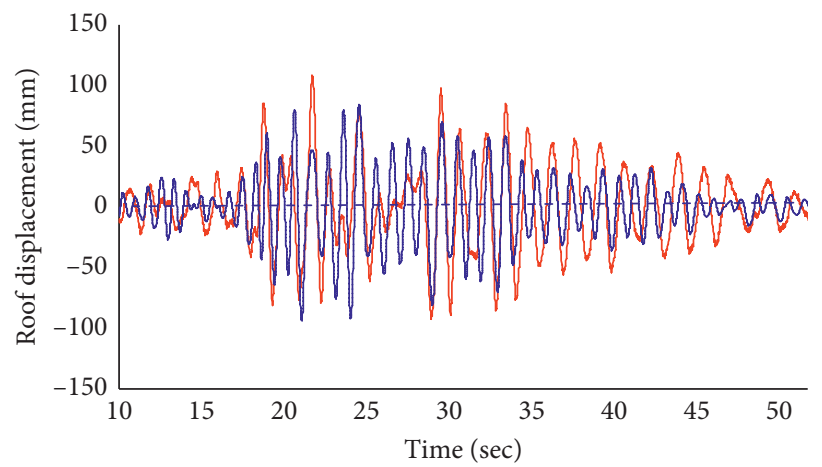

Model-3, 1.52\% roof drift (exp.)

_ Experimental

- - Analysis

FIgURE 14: Roof displacement time history response of tested RC frames. Figure 14 is reproduced from Ahmad et al. [13].
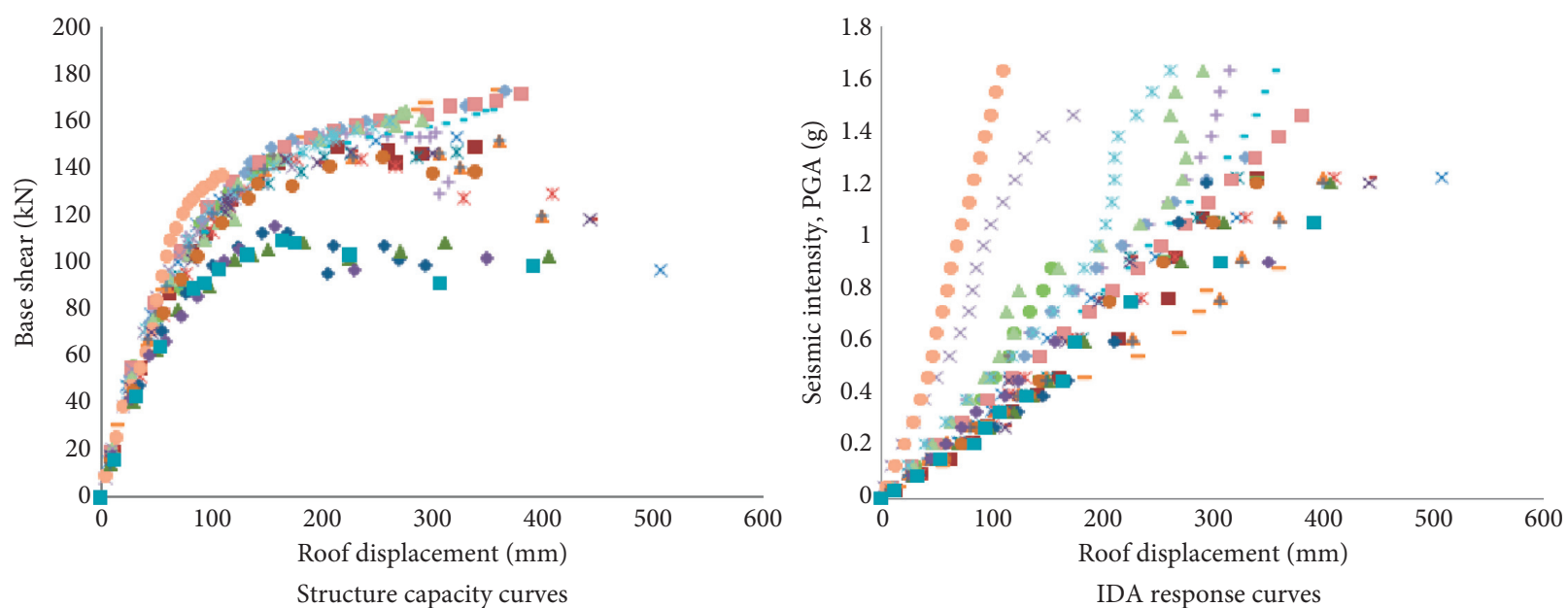

FIgURE 15: Structural response curves based on IDA technique for the frame building typology. 


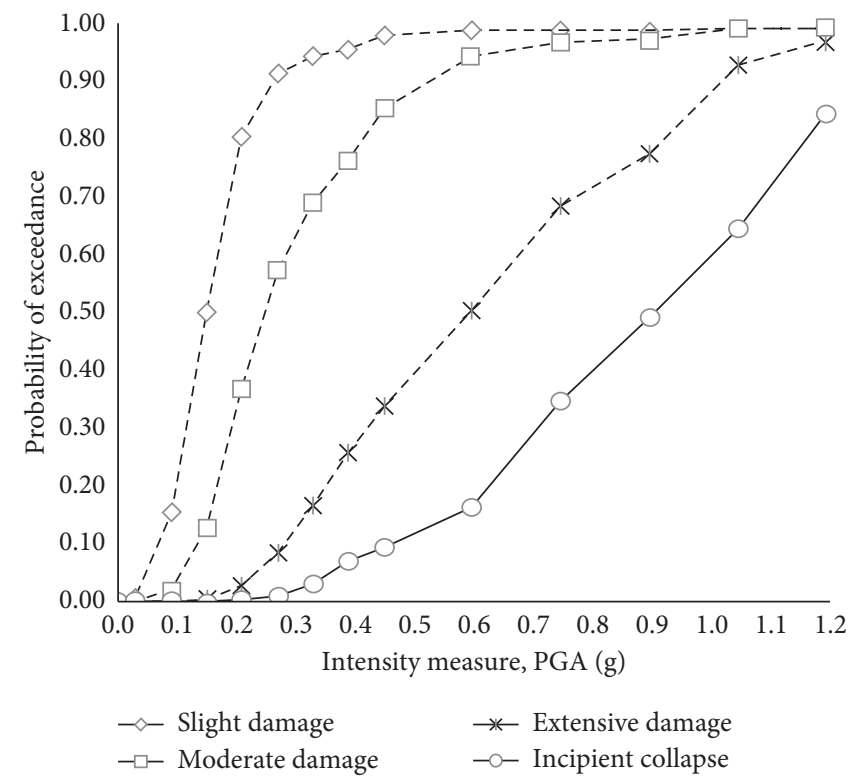

FIgURE 16: Fragility function development for the frame typology of Pakistan.

$$
P_{f}=\Phi(-\mathrm{RI})
$$

In equation (3), $P_{f}$ represents the exceedance, $\Phi$ is the function distribution criteria, and RI is the reliability index. The reliability parameter RI can be computed using the following equation:

$$
\begin{aligned}
\mathrm{RI} & =\frac{\lambda_{R}-\lambda_{s}}{\sqrt{\zeta_{R}^{2}+\zeta_{S}^{2}}}, \\
\lambda_{R} & =\ln \left(\mu_{R}\right)-0.5 \zeta^{2}, \\
\zeta & =\sqrt{\ln \left(1+\zeta_{R}^{2}\right)}, \\
\zeta_{R} & =\frac{\sigma_{R}}{\mu_{R}},
\end{aligned}
$$

where $R$ and $S$ are the capacity and demand limit state parameters, $\mu$ represents the average value, $\delta$ shows the variation function, and $\lambda$ represents the median parameter. All the parameters shown in equation (4) should be calculated for each capacity and demand limit state in order to obtain the reliability index RI. Once the reliability index has been computed for the specified limit state of the capacity and demand parameters, the probability of exceedance $P_{f}$ can be computed using equation (3). From the $P_{f}$ values, the corresponding fragility functions can be developed by multiplying them with the respective intensity level for the specified limit state. Figure 16 shows the developed prototype frame structure fragility curves. In order to fit the curves of fragility functions, the respective fitting has been performed as per the guidelines of HAZUS [16] and Baker [35], whereas the function crossing has been adjusted as per Porter's [36] recommendations. Figure 17 shows the final adjusted fragility functions.

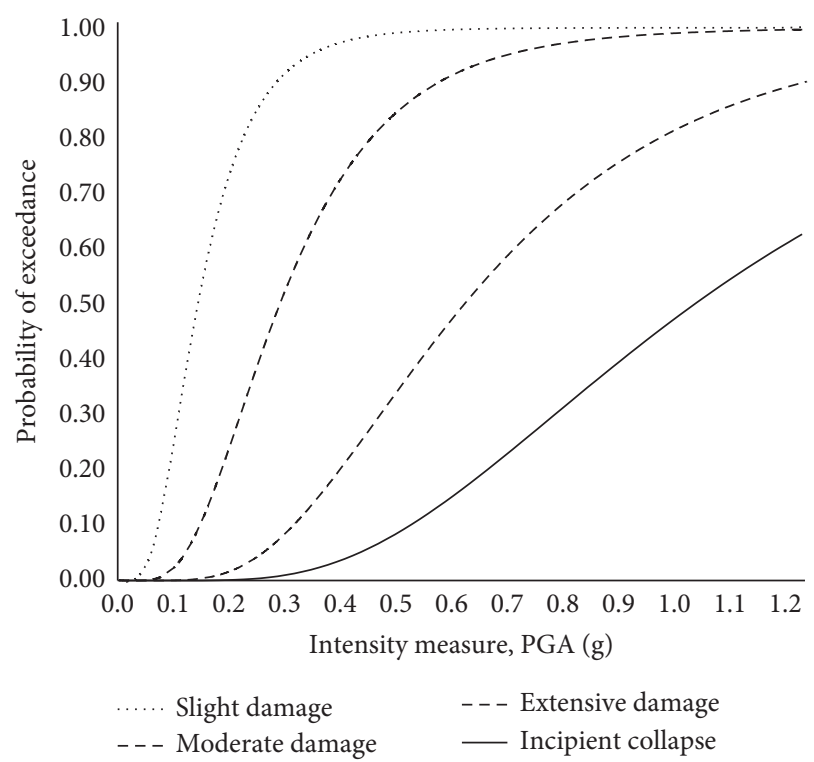

FIgURe 17: Fragility functions fitting based on Porter [36]. Median and standard deviation: 0.14 and 0.53 for slight damage, 0.29 and 0.53 for moderate damage, 0.62 and 0.53 for extensive damage, and 1.03 and 0.53 for incipient collapse.

5.3. Seismic Vulnerability Curve: Damage-to-Loss Conversion. In order to obtain meaningful results for loss analysis, vulnerability curves have been developed from respective fragility functions for each model. The vulnerability functions or curves basically relate repair to cost ratio (mean damage ratio (MDR)) of the structural system with earthquake shaking imposed to different intensity levels. The fragility functions derived for each frame structure were analyzed for specified seismic intensity levels and the corresponding damage states of the system or component. The damage states can be specified in terms of slight, 


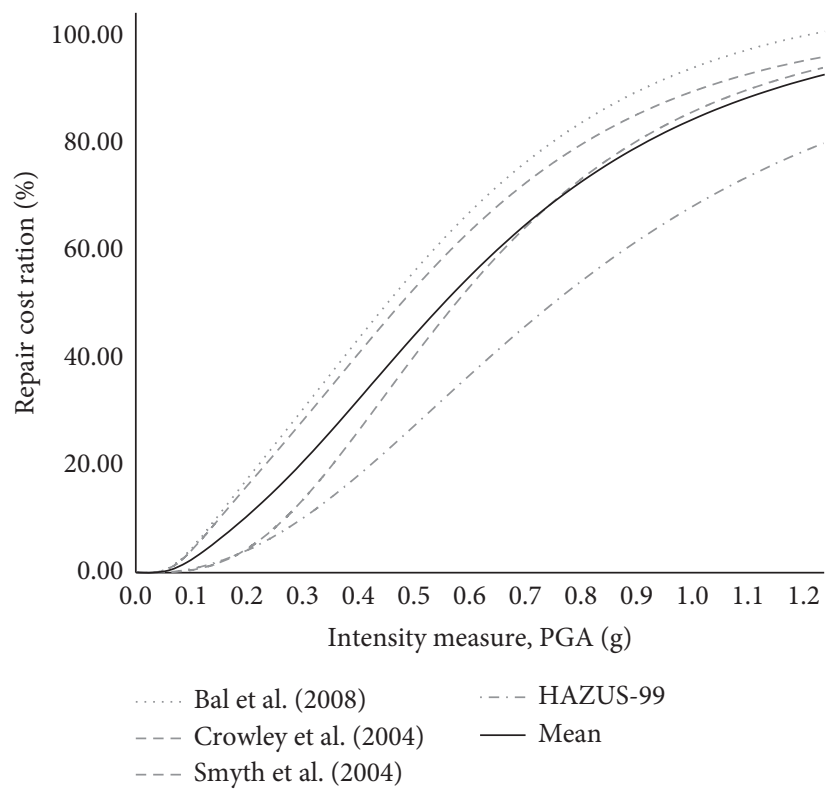

FIGURE 18: Seismic vulnerability curve derived for considered deficient RC frame building typology.

moderate, and extensive damages or partial or full collapse stage. The structural-damage to monetary-loss models developed [21] were used to transform the structural damage statistics to monetary losses, presented in terms of repair cost ratio [37], which is integrated over all building stocks in different damage states to calculate MDR [23] as mathematically given in the following equation:

$$
\mathrm{MDR}_{i}=\sum_{i=1}^{n} \sum_{j=1}^{m} \mathrm{DS}_{j} \times \mathrm{RCR}_{j},
$$

where in $\mathrm{MDR}_{i}$ represents the structural mean or average damage ratio, $\mathrm{DS}_{j}$ represents the damage state in terms of slight, moderate, significant or partial, or complete collapse state, and $\mathrm{RCR}_{j}$ represents the structural repair required for a particular damage level divided by the total cost of the structure and has been employed as per the existing repair to loss models [37]. The computed mean damage ratio or MDR has been further coupled with shaking levels in order to obtain the vulnerability functions. Furthermore, normalization has been performed by taking the average value in order to develop the selected building typology vulnerability function or curves, as also shown in Figure 18. On average, logarithmic standard deviation of about 0.40 is calculated to capture uncertainty in the mean seismic vulnerability curve. As per the proposed different damage-to-loss models and factors, the developed functions were also employed by considering the model-to-model uncertainties while defining the repair to cost factors [38]. The results of the vulnerability curve or functions are the repair to cost or RCR values which are coupled to a specified level of shaking and can be used in order to find the building repair or replacement costs. These can be further used for the direct earthquake loss estimation studies for the similar class of building systems.

\section{Conclusions}

Modern existing RC frame building typology in Pakistan is designed to the recent building code of Pakistan and detailed as per the requirements of [15] for special moment-resisting frame structures. However, due to improper execution, a number of construction defects (the use of low-strength concrete, lack of shear reinforcement in beam-column joints, and practicing reduced longitudinal and transverse reinforcements) can be found in constructed frames. Shake table tests performed on representative three low-rise two-story $1: 3$ reduced scale RC frames with construction deficiencies have revealed that such frame building typology exhibits mixed mechanism of column and beam member hinging followed by severe beam-column joint panel damage. This can result in significant vulnerability of the considered frame structures.

For the development and derivation of specific buildingbased typology damage scales, the dynamic test results of four experimental $\mathrm{RC}$ frame models were considered. The developed damage scales have been normalized with the FEMA specified damage levels which are usually employed for seismic performance evaluation. With light modification within the current data set, the limiting values of the corresponding drift limit states as per the FEMA recommendation have been considered for the selected building typology. The experimentally derived force-displacement capacity curve presented in terms of base shear coefficient (BSC) and roof drift was used for establishing performance levels (i.e., limit state drift and lateral strength).

Fragility functions were developed for the low-rise deficient frames common in Pakistan using a probabilistic-based methodlogy. For the considered methodology, the uncertainties in specifying the demand and capacity have also been considered. Using the fragility functions for the considered low-rise building typology, vulnerability curves in the form of repair to cost ratios have been evaluated. For the vulnerability 
curves, the existing damage-to-loss relationships have also been considered. The developed fragility and vulnerability curves can be used for the earthquake loss estimations of such building typology within the framework of risk assessments.

\section{Data Availability}

All data, models, or code generated or used during the study are available from the corresponding author upon request (Naveed Ahmad, naveed.ahmad@uetpeshawar.edu.pk). Items which may be requested are shake table test data of models (raw and processed data) and SeismoStruct numerical models.

\section{Conflicts of Interest}

The authors declare that they have no conflicts of interest.

\section{References}

[1] J. Avouac, F. Ayoub, S. Leprince, O. Konca, and D. V. Helmberger, "The 2005 Mw 7.6 Kashmir earthquake: sub-pixel correlation of ASTER images and seismic waveforms analysis," Earth and Planetry Science Letters, vol. 249, no. 3-4, pp. 514-528, 2006.

[2] R. Bilham, "Earthquakes in India and in the Himalaya: tectonic, geodesy, and history," Annals of Geophysics, vol. 47, no. 2-3, pp. 839-858, 2004.

[3] M. Rashid and N. Ahmad, "Economic losses due to earthquake-induced structural damages in RC SMRF structures," Cogent Engineering, vol. 4, no. 1, pp. 1-15, 2017.

[4] Y. I. Badrashi, Q. Ali, and M. Ashraf, Reinforced Concrete Buildings in Pakistan. EERI Housing Report No. 159, Earthquake Engineering Research Institute (EERI), Oakland, CA, USA, 2010.

[5] M. H. Arslan and H. H. Korkmaz, "What is to be learned from damage and failure of reinforced concrete structures during recent earthquakes in Turkey?" Engineering Failure Analysis, vol. 14, no. 1, pp. 1-22, 2007.

[6] S. Ates, V. Kahya, M. Yurdakul, and S. Adanur, "Damages on reinforced concrete buildings due to consecutive earthquakes in Van," Soil Dynamics and Earthquake Engineering, vol. 53, pp. 109-118, 2013.

[7] J. K. Bothara and K. M. O. Hiçyılmaz, "General observations of building behaviour during the 8th October 2005 Pakistan earthquake," Bulletin of the New Zealand Society for Earthquake Engineering, vol. 41, no. 4, pp. 209-233, 2008.

[8] H. Chaulagain, H. Rodrigues, E. Spacone, and H. Varum, "Seismic response of current RC buildings in Kathmandu valley," Structural Engineering and Mechanics, vol. 53, no. 4, pp. 791-818, 2015.

[9] B. Erdil, "Why RC buildings failed in the 2011 Van, Turkey, earthquakes: construction versus design practices," Journal of Performance of Constructed Facilities, vol. 31, no. 3, Article ID 04016110, 2016.

[10] T. Rossetto and N. Peiris, "Observations of damage due to the Kashmir earthquake of October 8, 2005 and study of current seismic provisions for buildings in Pakistan," Bulletin of Earthquake Engineering, vol. 7, no. 3, pp. 681-699, 2009.

[11] J. G. Ruiz-Pinilla, J. M. Adam, R. Pérez-Cárcel, J. Yuste, and J. J. Moragues, "Learning from RC building structures damaged by the earthquake in Lorca, Spain, in 2011," Engineering Failure Analysis, vol. 68, pp. 76-86, 2016.
[12] R. Spence, "Saving lives in earthquakes: successes and failures in seismic protection since 1960," Bulletin of Earthquake Engineering, vol. 5, no. 2, pp. 139-251, 2007.

[13] N. Ahmad, J. Akbar, M. Rizwan, B. Alam, A. N. Khan, and A. Lateef, "Haunch retrofitting technique for seismic upgrading deficient RC frames," Bulletin of Earthquake Engineering, vol. 17, no. 7, pp. 3895-3932, 2019.

[14] M. Rizwan, N. Ahmad, and A. N. Khan, "Seismic performance of compliant and noncompliant special moment-resisting reinforced concrete frames," ACI Structural Journal, vol. 115, no. 4, pp. 1063-1073, 2018.

[15] ACI 318-05, Building Code Requirements for Structural Concrete, American Concrete Institute, Farmington Hills, MI, USA, 2005.

[16] FEMA, HAZUS-MH, Technical Manual, Federal Emergency Management Agency (FEMA), Washington, DC, USA, 2003.

[17] N. Ahmad, A. Shahzad, Q. Ali, M. Rizwan, and A. N. Khan, "Seismic fragility functions for code compliant and noncompliant RC SMRF structures in Pakistan," Bulletin of Earthquake Engineering, vol. 16, no. 10, pp. 4675-4703, 2018.

[18] R. Pinho, "Nonlinear dynamic analysis of structures subjected to seismic actions," in Advanced Earthquake Engineering Analysis, A. Pecker, Ed., pp. 63-89, Springer, Berlin, Germany, 2007.

[19] SeismoSignal, "SeismoSignal-Software: a computer program for signal processing and analysis of accelerogram," 2016, https://www.seismosoft.com.

[20] N. Ahmad, Q. Ali, H. Crowley, and R. Pinho, "Earthquake loss estimation of residential buildings in Pakistan," Natural Hazards, vol. 73, no. 3, pp. 1889-1955, 2014.

[21] I. E. Bal, H. Crowley, and R. Pinho, "Detail assessment of structural characteristics of Turkish RC buildings stock for loss assessment models," Soil Dynamic and Earthquake Engineering, vol. 28, no. 10-11, pp. 914-932, 2008.

[22] HAZUS99, HAZUS 99, Technical and User's Manual, Washington, DC, USA, 1999.

[23] A. W. Smyth, G. Altay, G. Deodatis et al., "Probabilistic benefit-cost analysis for earthquake damage mitigation: evaluating measures for apartment houses in Turkey," Earthquake Spectra, vol. 20, no. 1, pp. 171-203, 2004.

[24] P. Quintana-Gallo, S. Pampanin, A. J. Carr, and P. Bonelli, "Shake table tests of under designed RC frames for the seismic retrofit of buildings-design and similitude requirements of the benchmark specimen," in Proceedings of the Eleventh U.S. National Conference on Earthquake Engineering, Los Angeles, CA, USA, June 2010.

[25] N. Ahmad, A. Shahzad, M. Rizwan et al., "Seismic performance assessment of non-compliant SMRF-reinforced concrete frame: shake-table test study," Journal of Earthquake Engineering, vol. 23, no. 3, pp. 444-462, 2019.

[26] N. Ahmad, "Fragility functions and loss curves for deficient and haunch-strengthened RC frames," Journal of Earthquake Engineering, pp. 1-30, 2019.

[27] SeismoMatch, "SeismoMatch-Software: a computer program for adjusting and matching accelerogram through wavelet based approach," 2016, http://www.seismosoft.com.

[28] J. Kim and J. M. LaFave, "A simplified approach to joint shear behavior prediction of RC beam-column connections," Earthquake Spectra, vol. 28, no. 3, pp. 1071-1096, 2012.

[29] Y. Kurose, "Recent studies on reinforced concrete beamcolumn joints in Japan." Phil M. Ferguson Structural Engineering Laboratory, PMFSEL Report No. 87-8, Department of 
Civil Engineering The University of Texas at Austin, Austin, TX, USA, 1987.

[30] S. Pampanin, G. M. Calvi, and M. Moratti, "Seismic behavior of R.C. beam-column joints designed for gravity only," in Proceedings of the 12th European Conference on Earthquake Engineering, vol. 74, Oxford, England, March 2002.

[31] M. J. N. Priestley, "Displacement-based seismic assessment of reinforced concrete buildings," Journal of Earthquake Engineering, vol. 1, no. 1, pp. 157-192, 1997.

[32] M. Sivaselvan and A. M. Reinhorn, "Hysteretic models for deteriorating inelastic structures," Journal of Engineering Mechanics, ASCE, vol. 126, no. 6, pp. 633-640, 2001.

[33] D. Vamvatsikos and C. A. Cornell, "Incremental dynamic analysis," Earthquake Engineering \& Structural Dynamics, vol. 31, no. 3, pp. 491-514, 2002.

[34] A. Der Kiureghian, "First-and second-order reliability methods," in Engineering Design Reliability Handbook, E. Nikolaidis, D. M. Ghiocel, and S. Singhal, Eds., CRC Press LLC, Boca Raton, FL, USA, 2005.

[35] J. W. Baker, "Efficient analytical fragility function fitting using dynamic structural analysis," Earthquake Spectra, vol. 31, no. 1, pp. 579-599, 2015.

[36] K. Porter, A Beginner's Guide to Fragility, Vulnerability, and Risk, University of Colorado Boulder and SPA Risk LLC, Denver, CO, USA, 2018.

[37] H. Varum, R. Pinho, and J. J. Bommer, "A probabilistic displacement-based vulnerability assessment procedure for earthquake loss estimation," Bulletin of Earthquake Engineering, vol. 2, no. 2, pp. 173-219, 2004.

[38] D. D’Ayala, A. Meslem, D. Vamvatsikos, K. Porter, T. Rossetto, and V. Silva, Guidelines for Analytical Vulnerability Assessment of Low/mid-Rise Buildings, Global Earthquake Model Foundation, Pavia, Italy, 2015. 